\title{
Mycoceros antennatissimus gen. et sp. nov.: a mitosporic fungus capturing pollen grains
}

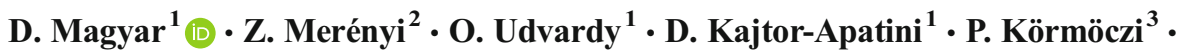 \\ A. Fülöp ${ }^{4} \cdot$ Z. Bratek ${ }^{2} \cdot$ L. Kredics ${ }^{3}$
}

Received: 22 December 2016 / Revised: 18 January 2017 / Accepted: 27 January 2017

(C) German Mycological Society and Springer-Verlag Berlin Heidelberg 2017

\begin{abstract}
Mycoceros antennatissimus gen. et sp. nov. is described and illustrated from pollen grains deposited on the bark of Elaeagnus angustifolia and Platanus $\times$ acerifolia in Hungary. This fungus is shown to capture pollen grains by its three-dimensional shape. It clearly shows seasonality and appears to be rare. The following factors determine its ecological niche: (1) the availability of fresh Pinaceae pollen grains deposited from the air on the bark of a nearby standing angiosperm tree with (2) water-retaining spongious bark, and (3) rainy weather. Conidia are mainly dispersed by stemflow rainwater, while they hardly become airborne. Direct polymerase chain reaction (PCR) from single conidia made it possible to perform molecular phylogenetic investigation in order to clarify its taxonomic relationship within the Ascomycota.
\end{abstract}

Section Editor: Marc Stadler

This article is part of the "Special Issue on ascomycete systematics in honour of Richard P. Korf who died in August 2016".

Electronic supplementary material The online version of this article (doi:10.1007/s11557-017-1275-3) contains supplementary material, which is available to authorized users.

D. Magyar

magyar.donat@gmail.com

1 National Public Health Center, BudapestAlbert F. s. 2-6, 1437, Hungary

2 Department of Plant Physiology and Molecular Plant Biology, Eötvös Loránd University, BudapestPázmány P. s. 1/c, 1117, Hungary

3 Department of Microbiology, Faculty of Science and Informatics, University of Szeged, SzegedKözép fasor 52, 6726, Hungary

4 Hungarian Meteorological Service, BudapestKitaibel P. s.1, 1024, Hungary
Keywords Hyphomycetes · Orbiliomycetes · Retiarius · Pollen degradation $\cdot$ Molecular phylogeny $\cdot$ Direct PCR

\section{Introduction}

In 2007, a fungus was found by the first author on Pinaceae pollen grains deposited in the bark fissures of Russian olive trees (Elaeagnus angustifolia L.) near (5 m away from) a Picea abies (L.) H. Karst. tree. Free conidia of this fungus were also observed when Alnus, Carpinus and Fagus twigs were washed (Révay and Gönczöl 2011, fig. 17-18.). In 2009, the sporulating colonies of this fungus were found again on Pinaceae pollen grains deposited in the bark fissures of a plane tree (Platanus $\times$ acerifolia (Aiton.) Willd.) near (14 m away from) a Picea abies tree. The fungus was repeatedly observed every year on this tree. In 2010, the fungus was found on Pinaceae pollen grains deposited under the bark of a yew (Taxus baccata L.) ca. $500 \mathrm{~m}$ from the abovementioned plane tree, between three Picea trees (at distances of $1.5,1.5$ and $3 \mathrm{~m}$, respectively).

Pollen parasitism is known in many fungi, including hyphomycetes, Chytridiomycota and basidiomycetes (Goldstein 1960; Chou and Preece 1968; Warren 1972; Hutchison and Barron 1997; Huang et al. 1999; Rodrigues Marques et al. 2013). Nutrients leached from pollen grains stimulate spore germination, even in plant-pathogenic fungi, which was described as the 'pollen effect' (Fokkema 1968; 1971a, b). Especially in environments with low nitrogen and phosphorus, utilisation of nutrients derived from pollen grains is substantial to allow fungi to complete decomposition, e.g. on litter (Stark 1972) or in oligotrophic lakes (Wurzbacher et al. 2014). Hyphomycete species being saprotrophs on pollen grains are common, but specialised parasites of them are rare. The present fungus is specialised to capture pollen grains and is described in a new genus because of its unique morphological and molecular features. 


\section{Materials and methods}

Small bark pieces were collected from adult, living Elaeagnus angustifolia $(\mathrm{N} 47.513685, \mathrm{E} 19.010648)$ and Platanus $\times$ acerifolia (N47.476308, E19.091952) trees, at a height of $1.5 \mathrm{~m}$ above ground, adjacent to spruce (Picea abies) during spruce pollen season (April-May) in Hungary. The samples were carried to the laboratory in sterile polyethylene bags. During microscopic investigations, deposited pollen grains were recovered from the bark using a wironit needle and a tape-lift method (with MACbond B 1200 pressure-sensitive acrylic strips, MACtac Europe S.A., Brussels). The tape-lift method was described previously in detail (Magyar 2008) and successfully used to explore fungal populations inhabiting bark fissures. Digital photomicrographs were taken with an Olympus BX-51 microscope at $600 \times$ magnification. Fungal structures were mounted on glass slides with lactic acid in methylene blue for microscopic examination. The type material is deposited in the Hungarian Natural History Museum, Budapest (BP). Other materials are deposited in the first author's collection (K.M.D.).

\section{DNA extraction and amplification}

For monospore DNA isolation, conidia were removed from the substrate with the above-mentioned pressure-sensitive tape, and then the tape was gently pressed to the surface of a pre-dried $2 \%$ Malt Extract Agar (MEA) medium. A $1 \times 1$-cm block was cut out of the MEA with the conidia and placed onto a microscopic slide. The surface of the agar block was scanned for free and clear conidia under $400 \times$ magnification. The conidia were transferred to $20 \mu \mathrm{L}$ Milli-Q water in a polymerase chain reaction (PCR) tube using a wironit needle under $200 \times$ magnification. One conidium was used to amplify a DNA region from the samples with the direct PCR method including a pre-PCR treatment step like the 'freeze-thaw method' (Bärlocher et al. 2010) in order to disengage the DNA. The phylogenetic analysis was based on two regions of the nuclear ribosomal RNA gene cluster. The internal transcribed spacer (ITS) and the large subunit (LSU) were amplified with the primers ITS1F/ITS7 (Gardes and Bruns 1993; Bertini et al. 1999) and LROR/LR5 (Vilgalys and Hester 1990), respectively. Because we had only conidia available, each sequence was derived from a single conidium and numbered as MD3-MD6. The pre-PCR treatment was as follows: PCR tubes with conidia were put into liquid nitrogen (around $-195{ }^{\circ} \mathrm{C}$, for $10 \mathrm{~s}$ ), thereafter for $20 \mathrm{~s}$ into the wells of a PCR machine (Little Genius TC-25/H, Bioier) and heated to $95^{\circ} \mathrm{C}$. This procedure was repeated $8-10$ times, followed by a termination step at $95{ }^{\circ} \mathrm{C}$ for $3 \mathrm{~min}$ and centrifugation $(10,000 \mathrm{~g}$, $1 \mathrm{~min}$ ). The PCR master mix was added into these PCR tubes. PCR was performed in a final volume of $50 \mu \mathrm{L}$, the components were as follows: $10 \times$ DreamTaq Green Buffer (Fermentas) with $20 \mathrm{mM} \mathrm{MgCl}(5.0 \mu \mathrm{L})$; dNTPmix (Fermentas) $(2 \mathrm{mM}$ each, $5.0 \mu \mathrm{L})$; primers for ITS or LSU $(0.01 \mathrm{mM}$ each, $1.0 \mu \mathrm{L})$, Milli-
Q water $(17.75 \mu \mathrm{L})$; DreamTaq polymerase (Fermentas) $(5$ unit $/ \mu \mathrm{L}, 0.25 \mu \mathrm{L})$. Thermocycling was carried out under the following conditions: $94{ }^{\circ} \mathrm{C}$ for $5.5 \mathrm{~min}, 40$ cycles of $94{ }^{\circ} \mathrm{C}$ for $18 \mathrm{~s}$, annealing at $51{ }^{\circ} \mathrm{C}$ for $30 \mathrm{~s}, 72{ }^{\circ} \mathrm{C}$ for $45 \mathrm{~s}$ and a final extension at $72{ }^{\circ} \mathrm{C}$ for $7 \mathrm{~min}$. The ABI Prism BigDye ${ }^{\mathrm{TM}}$ Terminator Cycle Sequencing Ready Reaction Kit v3.1 (Applied Biosystems) was applied for sequencing. Capillary gel electrophoresis was accomplished by an ABI PRISM 3100 Genetic Analyzer (Applied Biosystems), according to the instructions of the manufacturer (Biomi Ltd.). The electropherograms were visually verified using FinchTV 1.4.0 (Geospiza, Inc.; Seattle, WA, USA; http://www.geospiza.com). The GenBank accession numbers of the sequences from the new species (herb no. BP105172) obtained in this work are: MD3: KT186372 (ITS), MD4: KT186373 (ITS), MD5: KT186370 (LSU) and MD6: KT186371 (LSU).

\section{Phylogenetic analysis}

A BLAST search (Altschul et al. 1997) of the GenBank Nucleotide Database (National Center for Biotechnology Information, http://www.ncbi.nlm.nih.gov) was performed for each sequence obtained in this study and the most closely related taxa were involved in the subsequent phylogenetic analysis. In addition, sequences of known, morphologically similar pollencapturing fungi [type materials of Retiarius bovicornutus (IMI 223460) and R. superficiaris (IMI 223459)] were also included (Magyar et al. in preparation). The sequences most similar to our LSU sequence, and some sequences selected from the articles of Li et al. (2005), Spatafora et al. (2006) and Prieto and Wedin (2013), were aligned with the E-INS-I algorithm MAFFT (Katoh and Toh 2008). Phylogenetic analysis was conducted with both the ITS and LSU regions, but the ambiguously aligned sites mainly from the divergent ITS region were excluded using trimAl (Capella-Gutiérrez et al. 2009). Phylogenetic analysis under the maximum-likelihood (ML) criterion was conducted with the software RAxML-VI-HPC (Stamatakis 2006; Stamatakis et al. 2008) on the CIPRES Science Gateway v. 3.1 (Miller et al. 2010). The suitable substitution matrix for Bayesian analyses was selected with MrMODELTEST v2.3 (Nylander 2004). With regard to the Akaike Information Criterion (AIC), the best-fit likelihood models were found to be the GTR $+\mathrm{I}+\mathrm{G}$. Phylogenetic reconstructions performed by MrBayes 3.2.6 (Huelsenbeck and Ronquist 2001) ran in four chains with $10,000,000$ generations on CIPRES Science Gateway v. 3.1 (Miller et al. 2010). The average standard deviation of split frequencies was 0.0026 . Every 500th generation was sampled and the first $10 \%$ of the trees were discarded as burnin. A maximum clade credibility (MCC) tree was estimated from the combined posterior sample of trees using TreeAnnotator v1.6.1 (http://beast.bio.ed.ac.uk/TreeAnnotator). The phylogenetic trees were visualised with FigTree v. 1.3.1. (Rambaut 2009) and compared with each other in the statistical software $\mathrm{R}$ (version 3.0.2; $\mathrm{R}$ Core Team 2016) using the dendextend package (Galili 2015). 


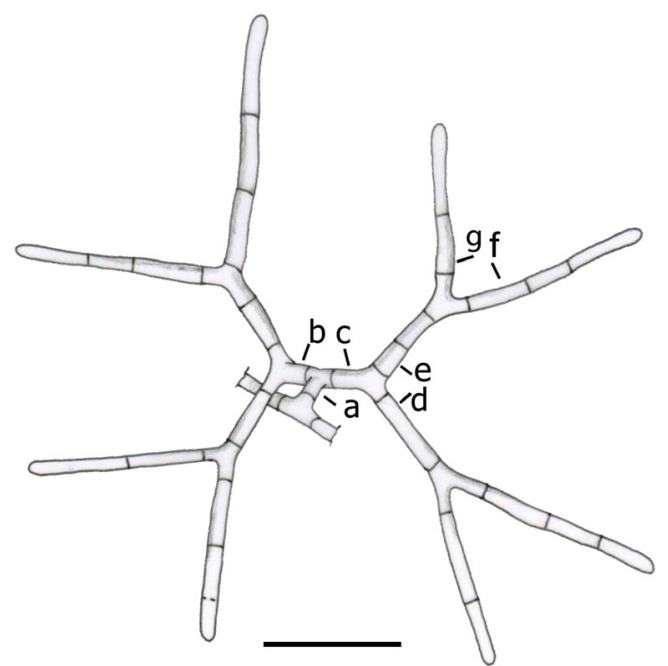

Fig. 1 Mycoceros antennatissimus. Conidial anatomy: $a$ main axis, $b, c$ arm of the primary dichotomy, $d, e$ arms of the secondary dichotomy (secondary arms), $f, g$ arms of the tertiary dichotomy (tertiary arms). $\mathrm{Bar}=20 \mu \mathrm{m}$

\section{Air sampling}

Airborne spores and pollen were collected using a Hirst-type sampler (Hirst 1952), $110 \mathrm{~m}$ away from a tree (Platanus) with
Mycoceros colonies, during a period of 8 years (2009-2016). Air is sucked into the sampler at a rate of $10 \mathrm{~L} / \mathrm{min}$ through a $2 \times 14$ $\mathrm{mm}$ orifice. Behind the orifice, the air flows over a rotating drum that moves past the inlet at $2 \mathrm{~mm} / \mathrm{h}$ and is covered with an adhesive-coated, transparent plastic tape. Particles in the air impact on the tape to give a time-related sample. Following its removal from the trap, the tape is divided into segments corresponding to $24-\mathrm{h}$ periods (48 $\mathrm{mm}$ in length). Each segment is mounted between a glass slide and cover slip using a mixture that contains gelatine, glycerol, phenol, distilled water and basic fuchsine. The samples are then examined by light microscopy and spores and pollen grains are generally identified at $400 \times$ or $600 \times$ magnification. Slides were examined along two longitudinal transects. The daily average (00:00-24:00 h) of airborne Pinaceae pollen concentration (pollen $/ \mathrm{m}^{3}$ ) was calculated.

\section{Stemflow sampling}

Stemflow rainwater samples were occasionally collected from an Elaeagnus angustifolia tree in a park in Budapest (N47.513685, E19.010648) between 2003 and 2008 and from a Platanus $\times$ acerifolia tree in another park (N47.476308, E19.091952) between 2008 and 2014. Depending on the
Fig. 2 Mycoceros antennatissimus. $\mathbf{a}-\mathbf{g}$ Development of conidia. Bar $=20 \mu \mathrm{m}$. h-k Development of erect aerial hyphae from colonised pollen grains. $\mathrm{Bar}=20 \mu \mathrm{m}$
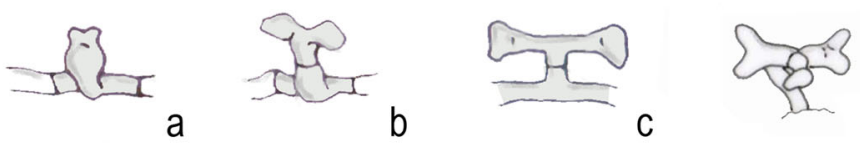

d

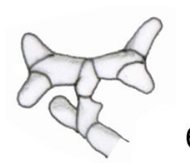

e
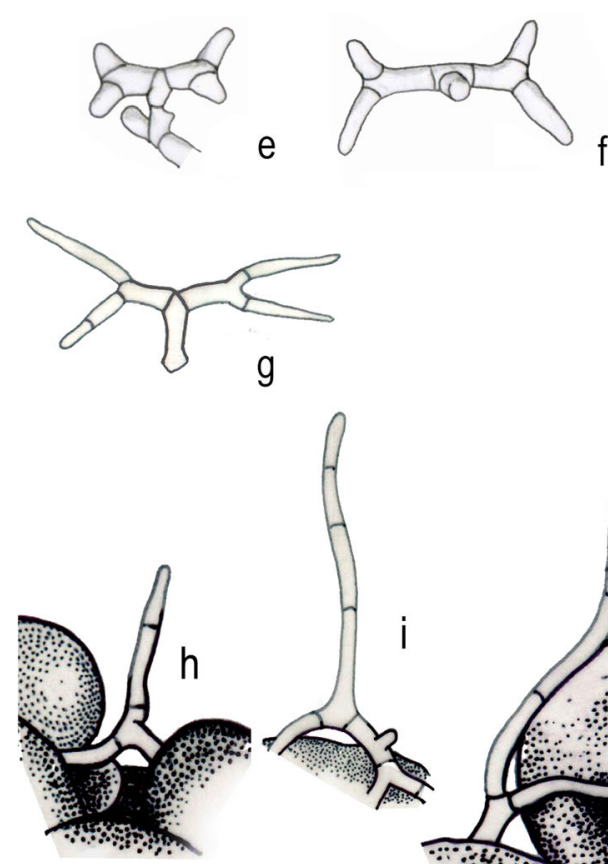
intensity of rainfall, various quantities of water could be collected $(2-10 \mathrm{~mL})$ into centrifuge tubes. One millilitre of FAA ( $50 \%$ ethanol, $5 \%$ glacial acetic acid, $10 \%$ formaldehyde) was added to each sample (Ingold 1975). Water samples were settled; one drop of the sediment was mounted on a microscope slide and allowed to dry. Lactophenol cotton blue was added to the dried sediment to prepare samples for further studies. A total of 11 rain samples were analysed.

Total rainfall $(\mathrm{mm})$ was measured with a rain gauge (Hellmann), daily average temperature $\left({ }^{\circ} \mathrm{C}\right)$ with a Vaisala thermometer (Budapest/Pestszentlörinc meteorological station) and moisture of bark of the trees (\%) with a moisture meter (Voltcraft FM-200) $24 \mathrm{~h}$ after rainfall.

Germination of fungal conidia was observed on $2 \%$ MEA with chloramphenicol. Conidia and Pinaceae pollen grains were transferred from a freshly collected tree bark with a sterilised wironit needle onto the surface of MEA. A $1 \times 1-\mathrm{cm}$ block was cut out of the MEA with pollen grains and conidia and placed onto a microscope slide, then placed and incubated vertically in a glass container with sterilised distilled water for $48 \mathrm{~h}$. Lactophenol cotton blue was added to the MEA block and covered with a cover slip and then photographed under $600 \times$ magnification. A simple, three-dimensional physical model was built of plastic rods to see the orientation and attachment positions of conidia on pollen grains.

\section{Results}

\section{Taxonomy}

Mycoceros D. Magyar \& Z. Merényi, gen. nov.

\section{MycoBank MB 819442}

Etymology: from Greek $\mu$ $\kappa \eta \varsigma, ~ m y k e ̄ s$ fungus; $\kappa \varepsilon \rho \alpha \varsigma$, keras, literally 'horn'.

Mycelium septate. Conidiophores integrated, micronematous, mononematous, smooth, hyaline. Conidia staurosporous, smooth, hyaline, multicellular. Conidium main axis straight,
Fig. 3 Mycoceros antennatissimus. a-i Conidia. Bar $=20 \mu \mathrm{m}$

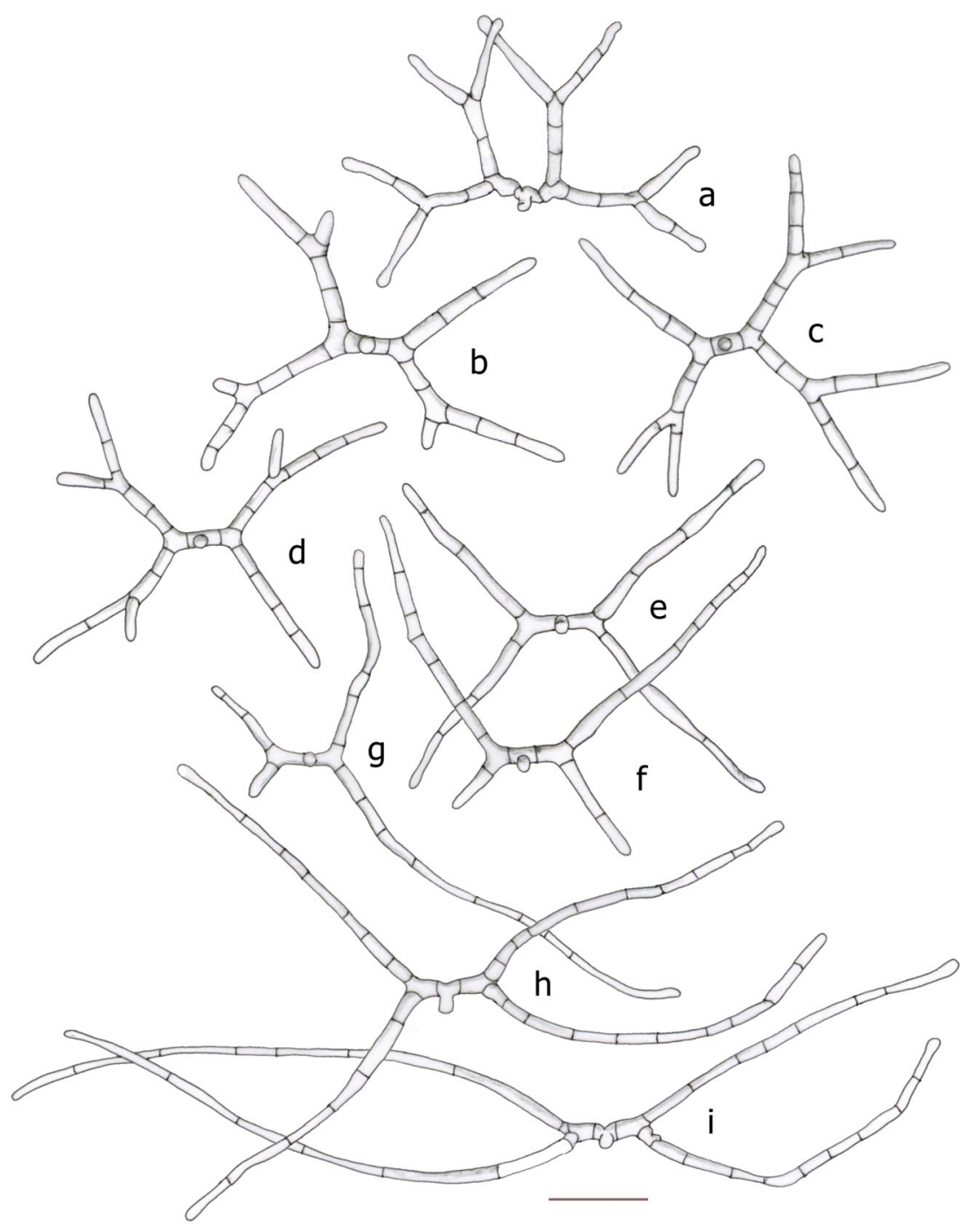


short, conidia forming a T-shaped primary dichotomy, each of the primary arms forming a secondary Y-shaped dichotomy, and its secondary arms often forming Y-shaped tertiary dichotomies, resulting in a 9-pike conidium.

Typus: Mycoceros antennatissimus

Mycoceros antennatissimus D. Magyar, sp. nov. Figures 1, 2 and 3. MycoBank MB819443

Etymology: antennatissimus (Latin) referring to the multibranched form of the conidia.

Mycelium septate, hyphae 1.2-2.4 $\mu \mathrm{m}$ wide. Conidiophores integrated, micronematous, mononematous, smooth, hyaline,
$2.3 \times 1.8 \mu \mathrm{m}$. Conidia staurosporous, smooth, hyaline, multicellular. Conidium main axis (Fig. 1a) straight, 0(-2)-septate, 2.0 $3.6(-8.5) \times 1.2-3.0 \mu \mathrm{m}$; the first cell slightly enlarged at the base (3.0-4.4 $\mu \mathrm{m})$. The conidia form a T-shaped primary dichotomy. Above the main axis, the conidium is slightly constricted (Fig. 2d, e, Fig. 3h). Each of the primary arms [Fig. 1b, c, 3.6$9.2 \times 2.0-4.3 \mu \mathrm{m}, 1(-3)$ septate] forms a secondary Y-shaped dichotomy, and its secondary arms [Fig. 1d, e, 13.0-22.7 $\times$ 2.0-3.0(-4.2) $\mu \mathrm{m}, 1-4$ septate, angle between primary and secondary arms: $82-112^{\circ}$, angle between two secondary arms 123 $139^{\circ}$ ] often form Y-shaped tertiary dichotomies (tertiary arms: Fig. 1f, g, 9.5-39.5 × 1.4-3.0 $\mu \mathrm{m}, 1-6$ septate, angle between

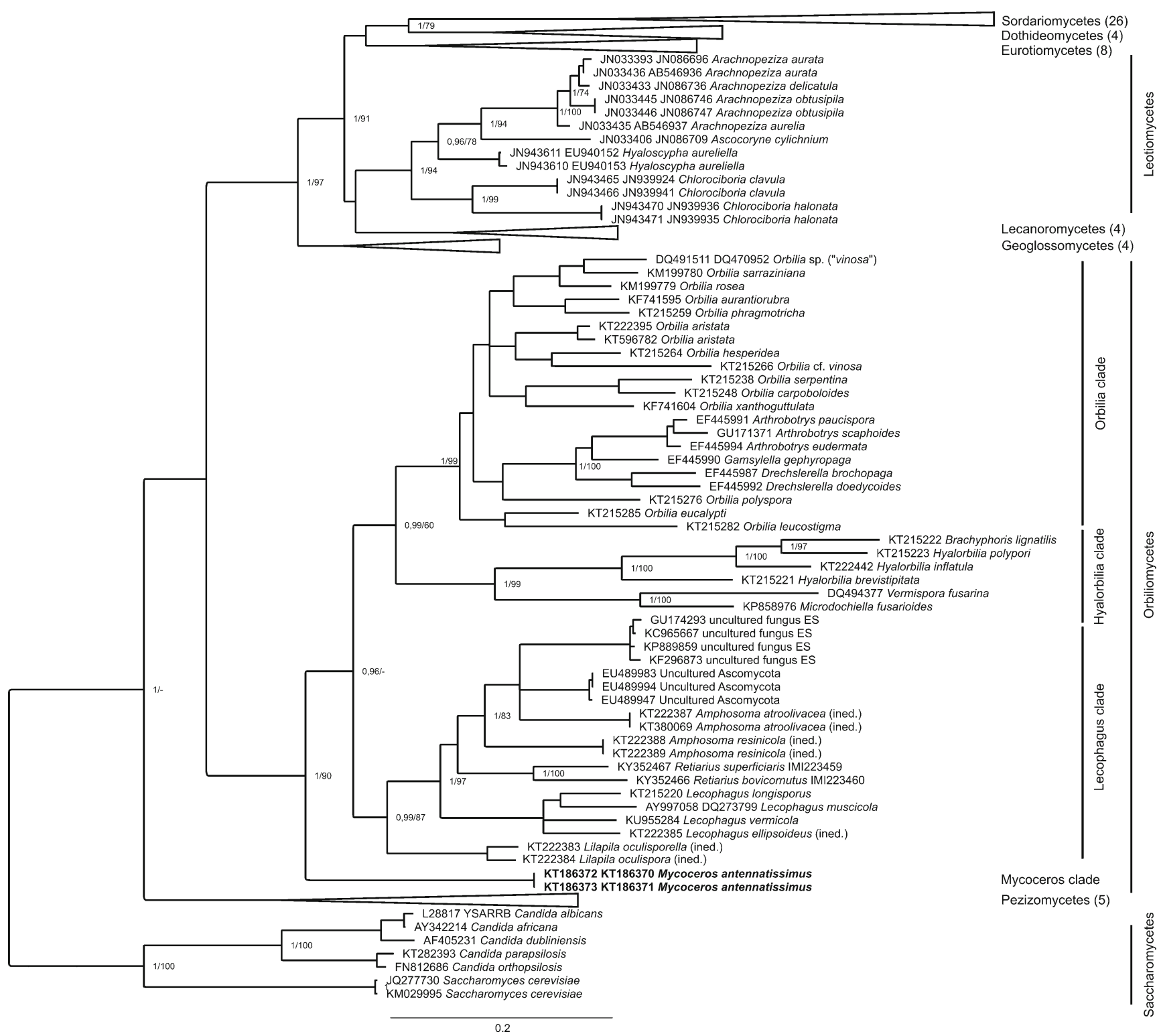

Fig. 4 Bayesian phylogenetic tree of Ascomycota based on trimmed ITS-LSU sequence alignment. Maximum credibility tree resulting from the MrBayes analysis of the trimmed ITS-LSU sequence alignment. Bayesian posterior probabilities (PP) and maximum likelihood (ML) bootstrap values separated by a slash (/) are provided at the major nodes in the tree as a measure of support. Only values where PP $>0.95$ and MP bootstrap support $>60 \%$ are shown, except in the case of the terminal branches. The collapsed part of the tree represents different fungal classes which are detailed in Supplementary Table 1. The scale bar means 0.2 expected nucleotide changes per site per branch 
tertiary arms: $54-109^{\circ}$ ), resulting in an up to 9-pike conidium. Tertiary arms are often oriented in the Z-direction; their terminal cells are either tapering to $0.9-1.3 \mu \mathrm{m}$ or cylindrical-rounded $(1.3-1.6 \mu \mathrm{m})$. Tertiary arms are sometimes lacking; in this case, the secondary arms become longer (up to $131 \mu \mathrm{m}$, Fig. 3e-i). Erect aerial hyphae (up to $135 \mu \mathrm{m}$ ) are also present in the colonies emerging from the hyphae. Long secondary arms of the conidia are also emerging from the surface of the pollen grains, which are apparently stabilised and supported by the primary and another secondary arm (Fig. 2i).

\section{Holotypus:}

Herbarium samples (BP 105172) colonies on pollen grains deposited on the bark of Platanus $\times$ acerifolia, HUNGARY, Budapest, 06 May, 2014, D. Magyar. GenBank Accession numbers: KT186372, KT186373 (ITS) KT186370, KT186371 (LSU).

Further specimens examined:

Herbarium samples no. K.M.D.07/2 colonies on pollen grains deposited on the bark of Elaeagnus angustifolia, HUNGARY, Budapest, Herman O. str., 10 Apr. 2007, D. Magyar;

Herbarium samples no. K.M.D.07/4 colonies on pollen grains deposited on the bark of Platanus $\times$ acerifolia, HUNGARY, Budapest, Albert F. str., 9 May, 2011, D. Magyar;

Herbarium samples no. K.M.D.07/5 colonies from pollen grains deposited on the bark of Platanus $\times$ acerifolia, HUNGARY, Budapest, Albert F. str., 12 May, 2011, D. Magyar;

Herbarium samples no. K.M.D.07/7b colonies on pollen grains deposited on the bark of Platanus $\times$ acerifolia, HUNGARY, Budapest, Albert F. str., 06 May, 2016, D. Magyar.

Mycoceros antennatissimus markedly differs from all previously described species. Conidia with secondary dichotomies superficially resemble those of Dwayaangam colodena Sokolski \& Bérubé, D. dichotoma Nawawi and D. quadridens (Drechsler) Subram., but differ in having a shorter, 0(-2)-septate main axis (Drechsler 1961; Nawawi 1985; Sokolski et al. 2006). It is thought that M. antennatissimus captures pollen grains by means of erect hyphae and conidial branches similar to that described in the two known species of Retiarius (Olivier 1978), from which it differs in having more dichotomies of arms. The generic separation is also based on molecular data (Fig. 4).

The two ITS sequences from MD3 and MD4 conidia and the two LSU sequences from MD5 and MD6 conidia were identical to each other by regions, which is an assurance that there was no contamination. The ITS sequence of Mycoceros antennatissimus comprises 534 nucleotides (ITS1 204 nt; 5.8S region $157 \mathrm{nt}$; ITS2 $173 \mathrm{nt}$ ). In the BLAST search for the ITS region with default settings, the sequence with the highest coverage was an Orbiliaceae sp. (Lilapila oculisporella G. Marson, Baral \& E. Weber ined., KT222383) with a query cover value of $73 \%$ and with only $80 \%$ similarity. The low coverage implies that mainly the $5.8 \mathrm{~S}$ region was alignable between Mycoceros ITS and GenBank sequences. This result shows that there is no ITS sequence in the databases that is closely related to our samples. In the BLAST search for the LSU region, the best matches (100\% cover) were some uncultured Ascomycota from savannah soils (USA, Texas, Vernon) with 92\% similarity (EU489983, EU490106 and EU489947).

The conidial morphology indicates that the fungus may belong to the genus Dwayaangam, for which only ITS sequences of one non-type species, $D$. colodena, are available in the international nucleotide sequence databases. However, these Dwayaangam ITS sequences are not alignable with our ITS sequences, except for the region of $5.8 \mathrm{~S}$ (156 bp). The pairwise p-distance between the $5.8 \mathrm{~S}$ regions of them is around $5.8-6.4 \%$, which excludes that they could belong to the same genus. In addition, the sister clade of Dwayaangam colodena, the genus Arachnopeziza (Sokolski et al. 2006),

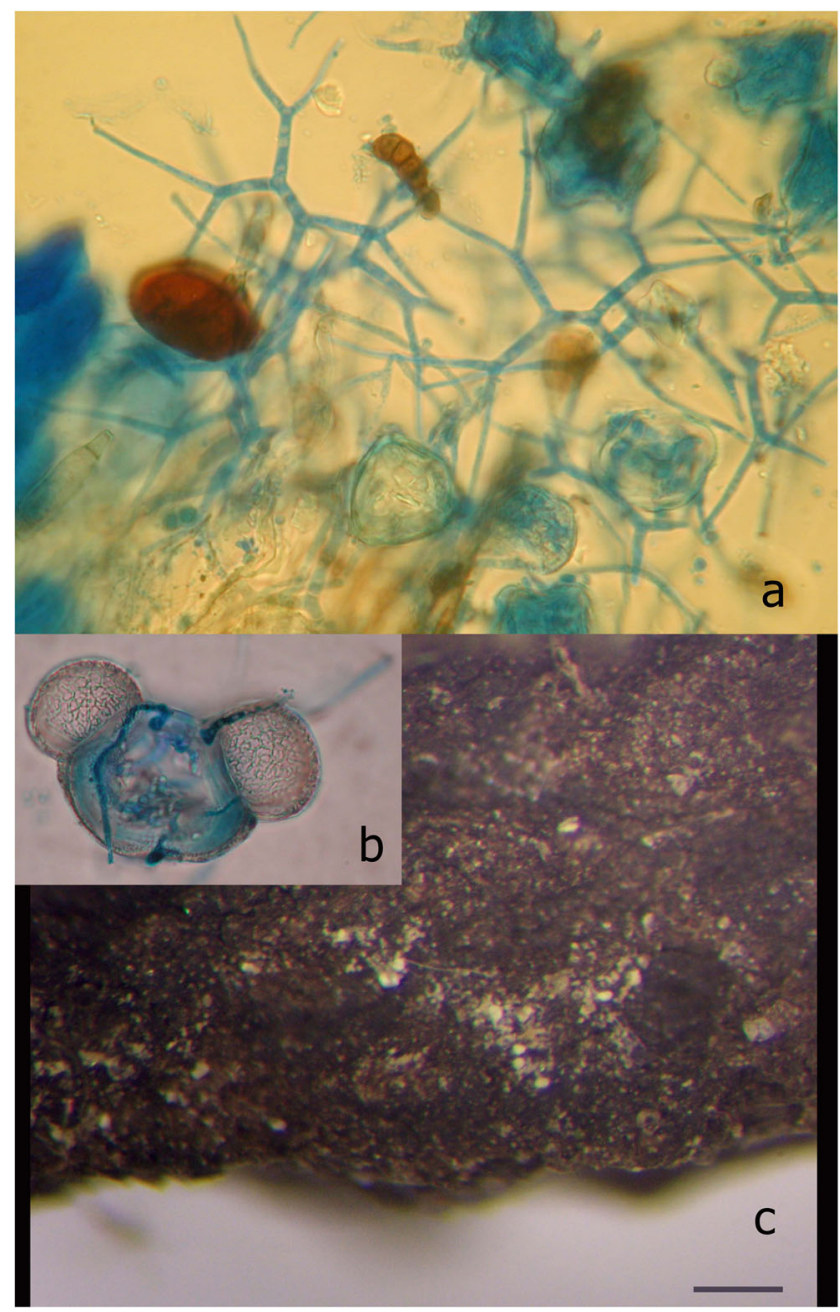

Fig. 5 Mycoceros antennatissimus. a Colony with angiosperm pollen. Bar $=20 \mu \mathrm{m}$. b Pinaceae pollen with penetrating hyphae. Bar $=20 \mu \mathrm{m}$. c Bark fissure with colonies on accumulated pollen grains. Bar $=200 \mu \mathrm{m}$ 
Table 1 Bark sample collections on three known host trees

\begin{tabular}{llll}
\hline & Elaeagnus & Platanus & Taxus \\
\hline Total number of samples & 23 & 55 & 12 \\
No. of positive samplings & 4 & 16 & 3 \\
No. of samplings in spring & 9 & 16 & 2 \\
Sampling periods & $2004-2012$ & $2009-2016$ & $2010-2016$
\end{tabular}

shows a high degree of separation from Mycoceros sequences in the phylotree based on ITS-LSU (Fig. 4).

Phylogenetic trees revealed similar topologies regardless of the method (Bayesian or maximum likelihood, ML). In the phylotree (Fig. 4), our samples represent a separate, highly supported monophyletic cluster within the Orbiliomycetes group. Based on the available sequences (ITS and LSU), it seems that Mycoceros sequences form a basal lineage, which is independent of the three major groups of Orbiliomycetes
(Orbilia, Hyalorbilia and Lecophagus clades). Therefore, the introduction of a new genus is also supported by molecular methods.

\section{Ecology}

Various pollen grains (Alnus, Ambrosia, Betula, Fagus, Morus, Platanus and different Pinaceae) were found in the bark fissures of Elaeagnus, Picea and Platanus. Mycoceros colonies were found in Elaeagnus and Platanus but none in Picea bark fissures. The moisture content of the tree bark was high (13.9-17.0\%) in the pollen-loaded bark fissures of a Platanus tree. (The fungus preferred the shady side of the tree facing the spruce.) Contrarily, the moisture content of the bark of the nearby Picea tree was lower (7.7-9.0\%). Mycoceros colonies were found on pollen aggregates containing various pollen grains (Alnus, Betula, Corylus, Cupressaceae/ Taxaceae, Pinaceae, Platanus, Fig. 5a). Colonies were different in size, containing 2 to 195 pollen grains, in which Platanus and Pinaceae pollen grains were dominant in having
Fig. 6 Seasonal occurrence of Mycoceros antennatissimus (samplings are marked with triangles, positive findings are marked with filled triangles), red line average temperature $\left({ }^{\circ} \mathrm{C}\right)$, black bars precipitation $(\mathrm{mm})$, grey bars airborne concentration of Pinaceae pollen grains. 20072008: samplings on Elaeagnus, 2009-2016: samplings on Platanus
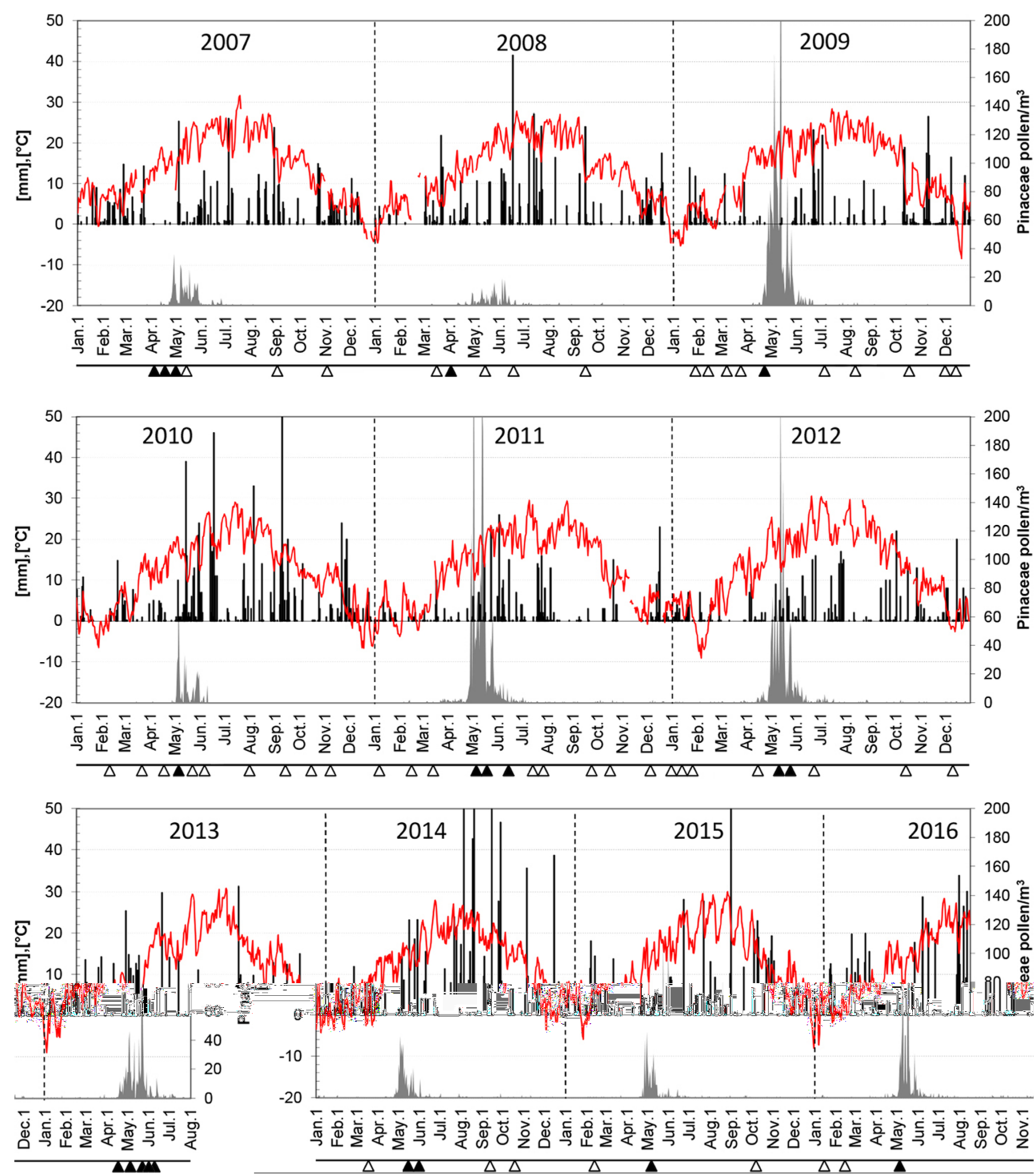
an average of $74.3 \%$ and $18.7 \%$, respectively. Extensive attempts failed to culture Mycoceros from colonised pollen grains on various artificial media (Malt Extract Agar, Dichloran Rose-Bengal Agar, Potato Dextrose Agar) was unsuccessful, like other methods (aerated, submerged incubation or incubation of wetted bark with latent colonies, with freshly harvested/freeze-stored Picea pollen grains).

\section{Discussion}

Single spore isolation techniques (Goh 1999; Choi et al. 1999) combined with monospore DNA extraction (Bärlocher et al. 2010; Magyar et al. 2016a) are found to be useful in taxonomic studies of fungi with poor or no growth on artificial media. When monospore DNA extraction is carried out, attention should be paid to the cleanness of the selected monospores: minute spores of common bark-inhabiting species, e.g. Trichoderma and Beauveria (Magyar, unpublished), could attach onto the selected spore and polluted DNA gives misleading results. Our monospore DNA extraction technique is a modification of the 'freeze-thaw method' (Bärlocher et al. 2010) using liquid nitrogen to disrupt spore walls before PCR, by having more repetitions with shorter times and a terminal centrifugation. The primers and PCR temperatures were only slightly different.

The bark of several tree taxa was sampled, including Elaeagnus, Platanus, Quercus, Acer, Robinia, Taxus,
Gymnocladus, Betula, Malus and Carpinus (in descending order of the number of samples collected), but no Mycoceros colonies were found. Only four trees, two (but neighbouring) Elaeagnus, one Taxus and one Platanus, gave positive results for M. antennatissimus. On these trees, the fungus was frequently present, e.g. in the case of Platanus, it was found in every year (2009-2016, Table 1). Apparently, M. antennatissimus is a rare fungus; however, the frequency of this fungus could be adequately determined if a high number of Elaeagnus, Platanus and Taxus trees with a Pinaceae neighbour were sampled in May.

Although the Elaeagnus and Platanus hosts were sampled in all years, no Mycoceros colonies were developed before April and after early June. Apparently, the optimal growth season for this fungus is May (Fig. 6). According to Révay and Gönczöl (2011), the other pollen-parasitic hyphomycete, Retiarius bovicornutus, has the highest conidial numbers in April, somewhat declining in May and low or nil in September. The latent period of this fungus is long (i.e. $84 \%$ of the year: summer, winter and early spring). It was suspected that its sporulation is affected by season. It should be noted that, during the extremely warm winter in 2015/2016, Pinaceae pollen appeared in the air and Mycoceros was found on 29th February (on Taxus).

We suppose that the availability of fresh (living) Pinaceae pollen is a key factor in the development of Mycoceros. Host trees always had a neighbour: a pollen-emitting pinaceous tree. Because the pollen grains of Pinaceae are large and heavy, they deposit near the source tree. Within $90 \mathrm{~m}, 91 \%$
Fig. 7 Mycoceros antennatissimus with pollen grains. a, b Two stages of attack: penetration and development of intracellular mycelium (in Alnus pollen). Conidia with pollen grains of: c Fraxinus, d two Fraxinus, e Platanus, f Corylus. Bar $=20 \mu \mathrm{m}$

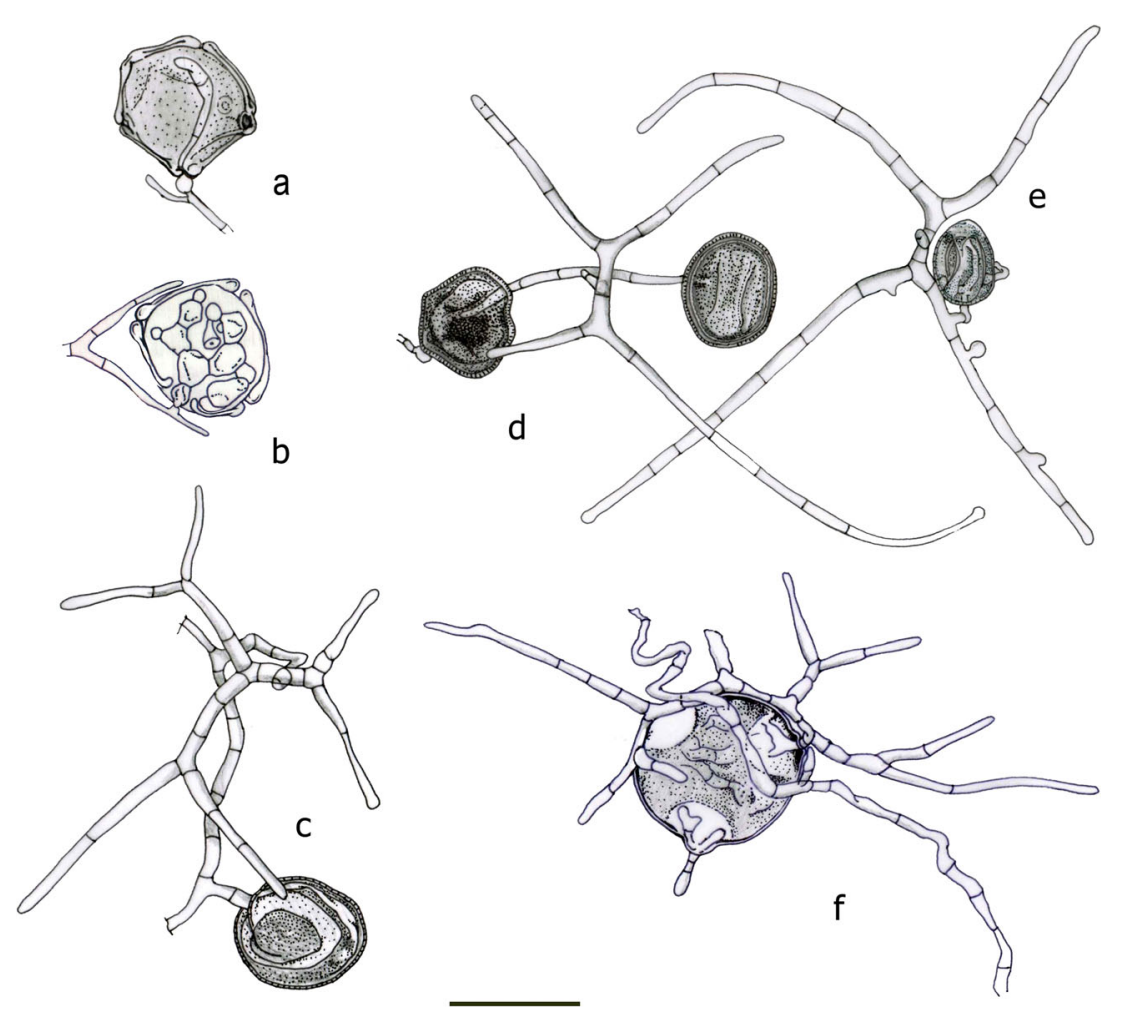


of the pollen grains of Picea abies come to rest (Di-Giovanni and Kevan 1991). Fresh (living) pollen grains appropriate for Mycoceros colonisation (Olivier 1978) could, therefore, only be found near Pinaceae trees. Despite the availability of other pollen grains before April, e.g. from neighbouring Betula and Corylus trees, the fungal colonies did not appear. We think that the presence of Pinaceae pollen is important, since this pollen is 2-3 times larger (thus containing more nutrients) than other common pollen grains (Betula and Corylus) accumulating on the bark during spring. It is supposed that the small size of Betula and Corylus pollen grains could not provide enough nutrients to enable the development of Mycoceros. However, climate could also be an important factor for starting germination. Temperature and precipitation were measured between 2007 and 2016. The fungus germinates in April from pollen grains, when temperature increases rapidly. Although the amount of precipitation was variable (monthly sum 1.4-35.6 mm, $\mathrm{SD}=12.7$ ), the fungus appeared even in dry years.

Chemotropic attraction of the fungal germ tubes to fresh Pinaceae pollen grain is plausible (Hutchison and Barron 1997). We also observed directional hyphae growing toward pollen grains. The fungus penetrates into Pinaceae pollen by breaking the exine between sacci at the thinned region (leptoma) (Fig. 5b). Angiosperm pollen grains are invaded by the fungus through wall openings (pori and colpi), as also shown by Huang et al. (1999). The mycelia coil around the pollen wall interior. The development of this intracellular mycelium in pollen grains shows toruloid, dichotomous morphology and it is similar to that illustrated by Olivier (1978, fig. 3f and g; compare it with our Fig. 7a, b). Once established in the first (possibly Pinaceae) pollen, the fungus develops conidia and directional hyphae to attack the nearby pollen grains (even small ones, e.g. Platanus pollen, Fig. 7e). The colonies are short-lived, and successful observation is limited to 2-3 weeks; thereafter, only moribund conidia are present scarcely until the middle of June. However, pollen grains filled with mycelia are present in the remaining period of the year. It was observed that even small pollen grains are able to preserve Mycoceros mycelia during the latent period of the fungus. Pollen grains emitted in mid summer, e.g. Ambrosia, were not colonised (unidentified, non-sporulating fungi were observed on these pollen grains as well, with penetrating hyphae originating from Pinaceae pollen). Our attempts to induce development and sporulation of Mycoceros from these colonised pollen grains failed constantly. Cultivation of colonised pollen grains on various artificial media was unsuccessful, like other methods (aerated, submerged incubation or incubation of wetted bark with latent colonies, with freshly harvested/freezestored Picea pollen grains).

Although the host trees were found near to pollen-emitting Picea trees, Mycoceros was not present on many other trees sampled (including Elaeagnus and Platanus), not even when blooming spruces were close to them. Therefore, it is thought that there are some other unknown factors needed to promote the colonisation of these fungi. It is known that the success of colonisation is determined by the nature and quantities of nutrients, together with physical features of the substratum, water availability, relative humidity and temperature (Cannon and Sutton 2004). The microclimate of bark fissures may be an important factor, but this needs more study.

No Mycoceros colonies were found in the bark fissures of Pinaceae trees, although deposits of various pollen grains (including fresh Pinaceae pollen) were present there and the host Platanus was in its proximity. Révay and Gönczöl (2011, fig. 17-18) found some free conidia of $M$. antennatissimus on various trees but not on Pinaceae, which can be confirmed by our observation. It is thought that the lack of Mycoceros colonisation on Pinaceae trees is due to the low moisture content of the spruce bark. Because of the canopy structure of the
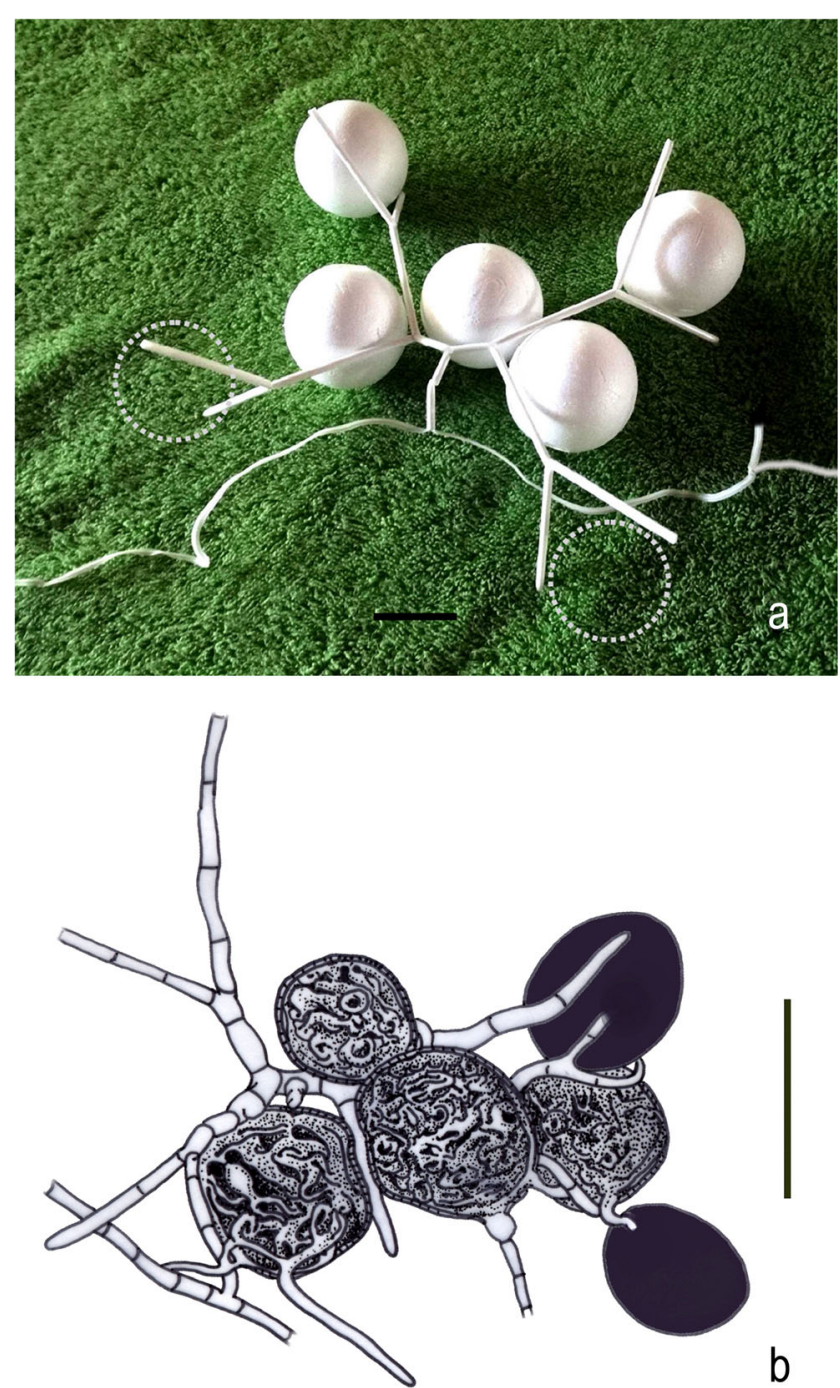

Fig. 8 Mycoceros antennatissimus. a Three-dimensional plastic model with pollen grains (two marked with dashed lines). b Clump of different pollen grains attached on the conidia. Bar $=20 \mu \mathrm{m}$ 
spruce, raindrops and stemflow rarely reach the bark of the bole. Among the bark cells of spruce there are resin droplets (20-30 $\mu \mathrm{m}$ in diameter) keeping the bark dry. Resin droplets were not found in the bark of the host trees. A range of growth inhibitory compounds were also reported from the wood of Pinus spp. (Erdtman 1952; Scheffer and Cowling 1966; Gunasekera and Webster 1983). These factors may inhibit the development of Mycoceros colonies in the pollen-filled bark fissures of pinaceous trees.

The aged bark of Elaeagnus, Platanus and Taxus is becoming thick with deep crackings. This texture is spongious and water-retaining. Water-filled bark promotes fungal growth on deposited pollen grains. There is a well-defined deposition zone in the bark fissures (Magyar 2008), where pollen grains, spores and detritus (microlitter) are accumulated and converted to crown humus. Fungi are living there consuming pollen and microscopical debris of fungal, plant and insect origin. Such fungi often have radiate conidia apparently adapted to dispersal in stemflow rainwater and anchoring on substrates (Magyar 2008; Magyar et al. 2016b). Bark fissures represent a habitat with high fungal diversity (Magyar 2008), where seasonal pollen input can be a substantial factor. In Pinaceaedominated environments, pollen deposition has been calculated to be in the range of $1-80 \mathrm{~kg} \mathrm{ha}^{-1} \mathrm{y}^{-1}$ (Hutchison and Barron 1997). Fungi may have important ecological implications there being the primary consumers of pollen grains. Further studies are, therefore, needed to understand fungal competition strategies on pollen grains in the accumulation zone of bark fissures.

Olivier (1978) described Retiarius superficiaris as growing on the adaxial surface of leaves and producing short erect hyphae by which it traps and becomes parasitic on anemophilous pollen grains. Similar erect hyphae are also present in M. antennatissimus. It is not clear, however, if the pollen grains are trapped directly in the air or just on the bark, after deposition. We suppose that the long arms of conidia and aerial hyphae could capture pollen grains from the air, similarly to plant trichomes which also increase the capture and retention of pollen grains (Roda et al. 2003). Pollen grains are also washed into the bark fissures by stemflow rainwater (D. Magyar, unpublished). We assume that the conidia of $M$. antennatissimus could capture pollen grains from the stemflow as well. Detached conidia are frequently found anchoring on the surfaces of pollen grains. The three-dimensional model showed that one conidium of $M$. antennatissimus could be in contact with seven pollen grains having a diameter of Platanus pollen. Secondary arms form a space to hold three pollen grains while tertiary arms oriented in the Z-direction allow to catch a further four pollen grains (Fig. 8a). Microscopic observations have also verified the position of pollen grains on conidia (Fig. 8b).

We frequently observed $M$. antennatissimus conidia in stemflow rainwater collected from Elaeagnus and Platanus host trees (10-20 Mycoceros conidia/mL). It is speculated that
Mycoceros conidia have a two-step dispersal tree-to-tree: first, the conidia are mobilised by stemflow and carried onto the bark surface, and are then carried by splashing rain drops to nearby trees. No doubt that Mycoceros conidia are mainly dispersed by stemflow for short distances, but, as our air samplings show, they hardly become airborne, as no Mycoceros conidia could be found in our air samples between 2009 and 2016.

Acknowledgements The authors are grateful to Gyula Dura and Anna Páldy, National Institute of Environmental Health for the financial support to complete the DNA analysis, Ágnes Révay, Hungarian Natural History Museum, Budapest for her valuable suggestions, Hans-Otto Baral, Tübingen, Germany for his valuable corrections and Gáti Zsófia for the technical assistance in the molecular methods. PK and LK were supported by grant GINOP-2.3.3-15-2016-00006 (Széchenyi 2020 Programme). ZM was supported by NTP-NFTÖ-16-0216 (National Talent Program of the Ministry of Human Capacities (EMMI), Human Capacities Grant Management Office (EMET) and GINOP- 2.1.1-152015-00115 (Széchenyi 2020 Programme).

\section{References}

Altschul SF, Madden TL, Schäffer AA, Zhang J, Zhang Z, Miller W, Lipman DJ (1997) Gapped BLAST and PSI-BLAST: a new generation of protein database search programs. Nucl Acids Res 25:33893402

Bärlocher F, Charette N, Letourneau A, Nikolcheva LG, Sridhar KR (2010) Sequencing DNA extracted from single conidia of aquatic hyphomycetes. Fungal Ecol 3:115-121

Bertini L, Amicucci A, Agostini D, Polidori E, Potenza L, Guidi C, Stocchi V (1999) A new pair of primers designed for amplification of the ITS region in Tuber species. FEMS Microbiol Lett 173:239 245

Cannon PF, Sutton BC (2004) Microfungi on wood and plant debris. In: Mueller GM, Bills GF, Foster MS (eds) Biodiversity of fungi: inventory and monitoring methods. Elsevier Academic Press, New York, pp 217-239

Capella-Gutiérrez S, Silla-Martínez JM, Gabaldón T (2009) trimAl: a tool for automated alignment trimming in large-scale phylogenetic analyses. Bioinformatics 25:1972-1973

Choi Y-W, Hyde KD, Ho WH (1999) Single spore isolation of fungi. Fungal Divers 3:29-38

Chou MC, Preece TF (1968) The effect of pollen grains on infections caused by Botrytis cinerea Fr. Ann Appl Biol 62:11-22

Di-Giovanni F, Kevan PG (1991) Factors affecting pollen dynamics and its importance to pollen contamination: a review. Can J For Res 21: $1155-1170$

Drechsler C (1961) Some clampless Hyphomycetes predacious on nematodes and rhizopods. Sydowia 15:9-25

Erdtman H (1952) Phenolic and other extraneous components of coniferous heartwoods; their relation to taxonomy. In: Wise LE, Jahn EC (eds) Wood chemistry, vol I. Reinhold, New York, pp 661-688

Fokkema NJ (1968) The influence of pollen on the development of Cladosporium herbarum in the phyllosphere of rye. Neth J Plant Pathol 74:159-165

Fokkema NJ (1971a) Influence of pollen on saprophytic and pathogenic fungi on rye leaves. In: Preece TF, Dickinson CH (eds) Ecology of leaf surface micro-organisms. Academic Press, New York, pp 277 282 
Fokkema NJ (1971b) The effect of pollen in the phyllosphere of rye on colonization by saprophytic fungi and on infection by Helminthosporium sativum and other leaf pathogens. Neth J Plant Pathol 77(Suppl 1):1-60

Galili T (2015) dendextend: an R package for visualizing, adjusting and comparing trees of hierarchical clustering. Bioinformatics 31:3718 3720

Gardes M, Bruns TD (1993) ITS primers with enhanced specificity for basidiomycetes - application to the identification of mycorrhizae and rusts. Mol Ecol 2:113-118

Goh T-K (1999) Single-spore isolation using a hand-made glass needle. Fungal Divers 2:47-63

Goldstein S (1960) Degradation of pollen by phycomycetes. Ecology 41: $543-545$

Gunasekera SA, Webster J (1983) Inhibitors of aquatic and aero-aquatic hyphomycetes in pine and oak wood. Trans Br Mycol Soc 80:121125

Hirst JM (1952) An automatic volumetric spore trap. Ann Appl Biol 39: 257-265

Huang HC, Kokko EG, Erickson RS (1999) Infection of alfalfa pollen by Botrytis cinerea. Bot Bull Acad Sin 40:101-106

Huelsenbeck JP, Ronquist F (2001) MRBAYES: Bayesian inference of phylogenetic trees. Bioinformatics 17:754-755

Hutchison LJ, Barron GL (1997) Parasitism of pollen as a nutritional source for lignicolous Basidiomycota and other fungi. Mycol Res 101:191-194

Ingold CT (1975) An illustrated guide to aquatic and water-borne hyphomycetes (Fungi Imperfecti) with notes on their biology. Freshwater Biol Assoc Sci Publ 30:1-96

Katoh K, Toh H (2008) Recent developments in the MAFFT multiple sequence alignment program. Brief Bioinform 9:286-298

Li Y, Hyde KD, Jeewon R, Cai L, Vijaykrishna D, Zhang K (2005) Phylogenetics and evolution of nematode-trapping fungi (Orbiliales) estimated from nuclear and protein coding genes. Mycologia 97:1034-1046

Magyar D (2008) The tree bark: a natural spore trap. Asp Appl Biol 89:716

Magyar D, Merényi Z, Bratek Z, Baral H-O, Marson G (2016a) Lecophagus vermicola sp. nov., a nematophagous hyphomycete with an unusual hunting strategy. Mycol Progr 15:1137-1144

Magyar D, Vass M, Li DW (2016b) Dispersal strategies of microfungi. In: Li DW (ed) Biology of microfungi. Springer International Publishing, pp 315-371

Miller MA, Pfeiffer W, Schwartz T (2010) Creating the CIPRES Science Gateway for inference of large phylogenetic trees. In: Proceedings of the Gateway Computing Environments Workshop (GCE), New Orleans, LA, 14 November 2010, pp 1-8

Nawawi A (1985) Some interesting hyphomycetes from water. Mycotaxon 24:217-226
Nylander JAA (2004) MrModeltest v2. Program distributed by the author. Evolutionary Biology Centre, Uppsala University. Available online at: https://github.com/nylander/MrModeltest2. Accessed 2012

Olivier DL (1978) Retiarius gen. nov.: phyllosphere fungi which capture wind-borne pollen grains. Trans Br Mycol Soc 71:193-201

Prieto M, Wedin M (2013) Dating the diversification of the major lineages of Ascomycota (Fungi). PLoS One 8:e65576

R Core Team (2016) R: A language and environment for statistical computing. R Foundation for Statistical Computing, Vienna, Austria. Home page at: https://www.R-project.org/

Rambaut A. (2009) FigTree, ver. 1.3.1. Available online at: http://tree.bio. ed.ac.uk/software/figtree/

Révay Á, Gönczöl J (2011) Canopy fungi ("terrestrial aquatic hyphomycetes") from twigs of living evergreen and deciduous trees in Hungary. Nova Hedwigia 92:303-316

Roda A, Nyrop J, English-Loeb G (2003) Leaf pubescence mediates the abundance of non-prey food and the density of the predatory mite Typhlodromus pyri. Exp Appl Acarol 29:193-211

Rodrigues Marques JP, Amorim L, Bellato Spósito M, Marin D, Appezzato-da-Glória B (2013) Infection of citrus pollen grains by Colletotrichum acutatum. Eur J Plant Pathol 136:35-40

Scheffer TC, Cowling EB (1966) Natural resistance of wood to microbial deterioration. Ann Rev Phytopathol 4:147-170

Sokolski S, Piché Y, Laitung B, Bérubé JA (2006) Streams in Quebec boreal and mixed-wood forests reveal a new aquatic hyphomycete species, Dwayaangam colodena sp. nov. Mycologia 98:628-636

Spatafora JW, Sung GH, Johnson D, Hesse C, O'Rourke B, Serdani M, Spotts R, Lutzoni F, Hofstetter V, Miadlikowska J, Reeb V, Gueidan C, Fraker E, Lumbsch T, Lücking R, Schmitt I, Hosaka K, Aptroot A, Roux C, Miller AN, Geiser DM, Hafellner J, Hestmark G, Arnold AE, Büdel B, Rauhut A, Hewitt D, Untereiner WA, Cole MS, Scheidegger C, Schultz M, Sipman H, Schoch CL (2006) A fivegene phylogeny of Pezizomycotina. Mycologia 98:1018-1028

Stamatakis A (2006) RAxML-VI-HPC: maximum likelihood-based phylogenetic analyses with thousands of taxa and mixed models. Bioinformatics 22:2688-2690

Stamatakis A, Hoover P, Rougemont J (2008) A rapid bootstrap algorithm for the RAxML web servers. Syst Biol 57:758-771

Stark N (1972) Nutrient cycling pathways and litter fungi. Bioscience 22: $355-360$

Vilgalys R, Hester M (1990) Rapid genetic identification and mapping of enzymatically amplified ribosomal DNA from several Cryptococcus species. J Bacteriol 172:4238-4246

Warren RC (1972) The effect of pollen on the fungal leaf microflora of Beta vulgaris L. and on infection of leaves by Phoma betae. Neth J Plant Pathol 78:89-98

Wurzbacher C, Rösel S, Rychła A, Grossart H-P (2014) Importance of saprotrophic freshwater fungi for pollen degradation. PLoS One 9: e94643 